\title{
EL TURISMO EN CUBA. UN ANÁLISIS GEOGRÁFICO
}

\author{
por \\ SALINAS CHÁlZZ, E. *, MUNTET I CERDAN, LI.** \\ *(Facultad de Geografía, Universidad de La Habana, Cuba.) \\ ** Departamento de Geografía de la Universidad de Girona. Escuela Oficial de Turismo de la \\ Generalitat de Cataluña, España)
}

\section{RESUMEN}

El turismo, como industria, tiene sus orígenes en Cuba a principios del s. XX y su desarrollo va estrechamente ligado a los cambios económicos, sociales y políticos ocurridos en la isla a lo largo de este siglo. La Revolución de 1959 supondrá la desaparición del turismo internacional que no se recuperará, lentamente, hasta los años 70 y 80 y, de una forma acelerada, a partir de 1989 con la caída del bloque socialista, al ser considerado la única alternativa para la recuperación económica del país. Aunque en los últimos años se ha introducido la planificación ambiental en el desarrollo turístico, la distribución de la capacidad hotelera, refleja una fuerte polarización de la oferta en las playas y las ciudades, consagrando el modelo de turismo litoral existente en el resto del Caribe, con el riesgo de hipotecar un futuro desarrollo alternativo de otras modalidades turisticas.
Palabras clave: Caribe, Cuba, turismo, Revolución, litoral, sol y playa

\section{ABSTRACT}

The tourist industry in Cuba dates from the beginning of the twentieth century and its development is closely linked to the economic, social and political changes that have taken place on the island throughout this century. The 1959 Revolution signalled the disappearance of international tourism. A gradual recovery in tourism began in the 1970 s and 1980s and rapid growth followed the fall of the socialist block in 1989 when tourism was considered as the only way to achieve the economic regeneration of the country. Despite recent environmental policies in tourism development, the distribution of hotel capacity reflects a marked polarisation of the tourism offer along the seafront and in the cities. The existing Caribbean model of coastal tourism is thus being 
reinforced, with the subsequent risk of jeopardising alternative future development of other forms of tourism.

KeY words: Caribbean, Cuba, tourism, Revolution, littoral, sun and sand

\section{INTRODUCCIÓN}

El turismo considerado por muchos como la actividad económica más dinámica del siglo $\mathrm{XX}$, es un fenómeno característico e irreversible de nuestra época, con especial importancia en el desarrollo de nuestra sociedad, entre otras causas, por la gran cantidad de personas que en él participan y su amplia repercusión en lo ecológico, económico, social y cultural.

El desarrollo del turismo a escala mundial y en el Caribe es una realidad $y$, de hecho, constituye el modo de vida principal para no pocos países en desarrollo. Sus efectos multiplicadores pueden y deben entonces ser aprovechados en beneficio de sus economías.

Según la Organización Mundial del Turismo (OMT) en 1.997 se reportaron más de 610 millones de llegadas e ingresos superiores a los 440.000 millones de dólares (excluido el transporte internacional). A la vez que se está consolidando una etapa de cambios en la que se espera pasar del modelo tradicional de turismo de masas desarrollado en las décadas de 1.950 a 1.980 con grandes infraestructuras y sustentado en el auge del transporte aéreo, al conocido como "consumo masivo de naturaleza" que, en el cambio de siglo, busca acercar al hombre urbano a la naturaleza.

Para las primeras décadas del siglo XXI se espera que continúen las tendencias de crecimiento del turismo, según "Turismo Panorama 2.020" (OMT,1.998), las llegadas de turistas alcanzaran en ese año los 1.600 millones e ingresos por 2 billones de dólares lo que implica tasas de crecimiento anual medio sostenido del 4,3 y $6,7 \%$ respectivamente.

Las tendencias del turismo en el siglo XXI muestran que, sin despreciar la supervivencia del turismo de playa, se producirá el crecimiento del turismo de naturaleza, la diversificación de las ofertas, la revalorización del turismo activo frente al turismo pasivo y el desplazamiento a destinos cada vez más lejanos e insólitos (OMT, 1.998). Ésto implica un fuerte reto para los países receptores y en especial para aquellos que, como el Caribe insular, han basado su desarrollo turístico en la explotación y masificación del turismo de sol y playa.

El turismo es un fenómeno espacial, hecho que con frecuencia se minimiza o se obvia, debido al predominio de la concepción y análisis económico del mismo. La incorporación del territorio al turismo se realiza mediante la conversión de sus recursos en productos, la creación de atracciones y servicios, y su 
promoción y comercialización (VERA y otros, 1.997).

Es por ésto que el análisis del turismo no debe realizarse sólo a partir de las cifras de llegadas, ingresos, etc., sino que debe estar estrechamente relacionado con el estudio del espacio turístico. A la hora de planificar el desarrollo del turismo en un espacio receptor se ha de tomar en cuenta, además de los elementos económicos, socio-culturales y ambientales, el papel de la estructura territorial sobre la que se quiere implantar la actividad, ya que finalmente las actividades turísticas se desarrollarán en un espacio determinado, aunque las relaciones económicas y sociales que se establezcan rebasan este espacio (VERA y otros, 1.997).

\section{TURISMO EN EL CARIBE}

En los últimos años se ha producido en el contexto internacional un incremento en la atracción simbólica de las islas (especialmente tropicales) afianzado en una gran promoción turística que las señala como lugares paradisíacos, convirtiéndolas en sitios de esperanzas, exotismo y aventuras. Esto se ha visto incrementado por el hecho de que las islas se han beneficiado por los procesos principales que han caracterizado el auge del turismo en los últimos años y que, según GEORGE CAZES y otros autores, son: apropiación, aislamien to y mis- tificación (CAzes, G. citado por Salinas Ed. y Er. Salinas, 1.998).

Las islas tropicales y en particular el Caribe presentan como recursos turísticos más importantes sus altos valores estéticos, relacionados con la existencia de fenómenos naturales espectaculares como son: las playas y los arrecifes coralinos, la exuberancia de su flora y fauna desarrollada en condiciones de aislamiento y lejanía con una alta biodiversidad y endemismo y por último sus extraordinarios valores socio-culturales.

En contraste con otros territorios insulares del mundo, más aislados, las islas del Caribe, situadas estratégicamente, han experimentado un prolongado e intenso proceso de crecimiento demográfico y explotación de sus recursos. Por más de 500 años desde los viajes de Colón, las islas del Caribe han servido como puente de contacto entre Europa, África, América del Norte y del Sur, participando también de las luchas políticas entre sus metrópolis, y pasando por un largo y dificil proceso de descolonización que aún no ha terminado (SAlinas, Rua y AceVedo, 1.999).

El fuerte crecimiento de la población, la mezcla de culturas: europeas, africanas, asiáticas y aborígenes, acompañadas por siglos de monoculturas de plantación y el más reciente impacto del turismo de masas, han provocado la progresiva degradación y pérdida de los recursos naturales, la disminución de la 
diversidad biológica y de la productividad de sus geosistemas, así como el abandono de las prácticas tradicionales del manejo de sus recursos.

En este espacio geográfico, compuesto por 29 estados independientes con un área superior a los $235.000 \mathrm{Km}^{2}$, una población que sobrepasa ya los 36 millones de habitantes y la más alta biodiversidad por $\mathrm{Km}^{2}$ del hemisferio occidental, se ha consolidado uno de los mayores desarrollos turísticos del planeta a partir de la segunda mitad del siglo $\mathrm{XX}$, convirtiéndose el turismo en el componente socio-económico esencial de la mayoría de los países del Caribe.

Según cifras de la OMT, en 1.997 la llegada de turistas a la región fue de más de 15 millones, con un crecimiento del $6,4 \%$ (superior a la media mundial que fue del $3 \%$ ) y un aumento en los ingresos del $4,6 \%$ con un valor de 13.600 millones de dólares (excluyendo el transporte internacional). Para el año 2.020 se prevé la llegada de 40 millones de turistas a la región, lo que implica un gran reto por los fuertes impactos ambientales, económicos, sociales y culturales que ésto generará.

El problema fundamental de este fuerte crecimiento en el Caribe es que se concentra principalmente en las áreas costeras asociado a sus atractivas playas y fondos marinos, sus condiciones climáticas y sus aguas cálidas. Pero es aquí, precisamente, donde también se concentra la mayor parte de la población y las principales ciudades, muchas de ellas con serios problemas ambientales asociados a su rápido y anárquico crecimiento en las últimas décadas.

Existen diferencias entre los países de la región en cuanto al número de turistas recibidos, ingresos, etc. lo que establece diferencias a la hora de abordar el futuro desarrollo de un turismo sustentable en el área (objetivo básico de la Asociación de Estados del Caribe), que deberá ser soportable en lo ecológico, factible en lo económico y equitativo desde una perspectiva ética y social para la población de las islas. Muchos especialistas señalan como una importante oportunidad para el Caribe insular aprovechar el creciente interés de los turistas por descubrir lo natural y su mayor conciencia sobre la protección del medio ambiente, captando un segmento de turistas que según se pronostica continuará creciendo en los próximos años y que se asocia al turismo de naturaleza, lo que permitirá diversificar la oferta y afianzarse como una región con un turismo de excelencia (SALINAS, Er., 1.999).

\section{DESARROLLO DEL TURISMO EN CUBA}

No puede realizarse ningún estudio del turismo en Cuba sin analizar la relación existente entre la industria turística y los cambios económicos, 
Figura 1. Llegada de Turistas a Cuba, 1925-1998

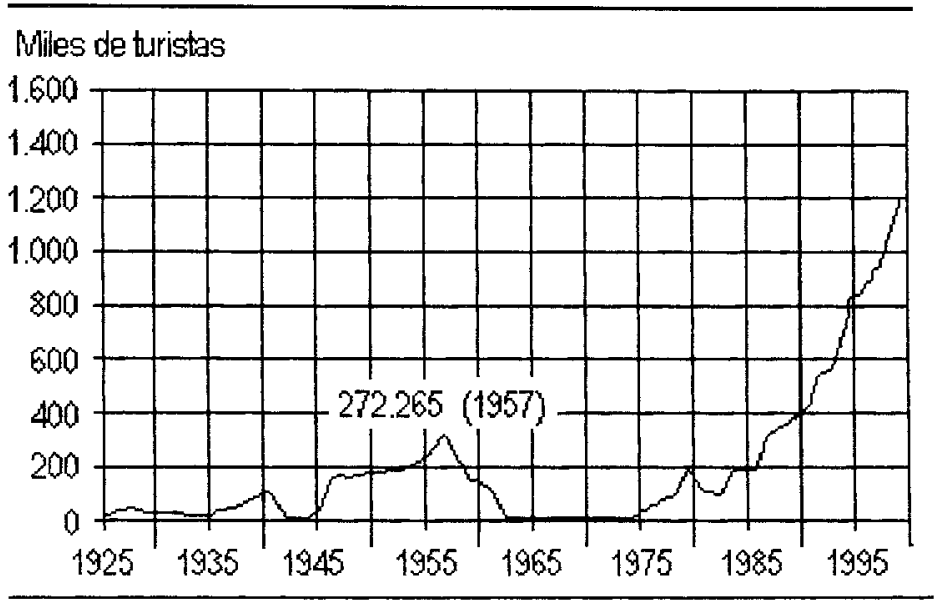

Fuente: Salinas, E. (1998); Mundet, Ll (1998); Caribbean Tourism Organisation

sociales y políticos que se han producido a través de su historia.

El turismo en Cuba tiene una larga tradición y sus orígenes se remontan a la primera mitad del siglo XIX. Sin embargo, en todo ese siglo y en la primera mitad del siglo XX, el desarrollo del turismo se caracterizó por la inexistencia de políticas para aumentar o mantener los avances alcanzados durante determinados periodos (SALINAS ER. Y Benavides, 1.995). La creación de la Comisión Nacional para el Fomento del Turismo en Agosto de 1.919, se considera que marca el inicio del turismo como industria. A partir de ese momento se intenta organizar la actividad turística e incrementar la construcción de nuevas instalaciones, apoyándose en el auge económico experimentado en el país como consecuencia del alza en los precios del azúcar en el mercado internacional.

Paralelamente a este proceso, la industria turística en el Caribe comienza su despegue con un crecimiento sostenido del número de turistas en el periodo entre las dos guerras mundiales, con excepción de algunos años de depresión de la actividad, asociados a las crisis económicas mundiales, especialmente la de 1.929 que produjo un impacto negativo sobre el turismo en la región entre los años 1.932 y 1.935.

Como se puede apreciar en la Figura 1 (a pesar de factores internos relacionados con la estructura económica y política del país, e impulsado además 
Figura 2. Evolución de los Ingresos por Turismo y del $\mathbf{n}^{\circ}$ de Camas de Hotel

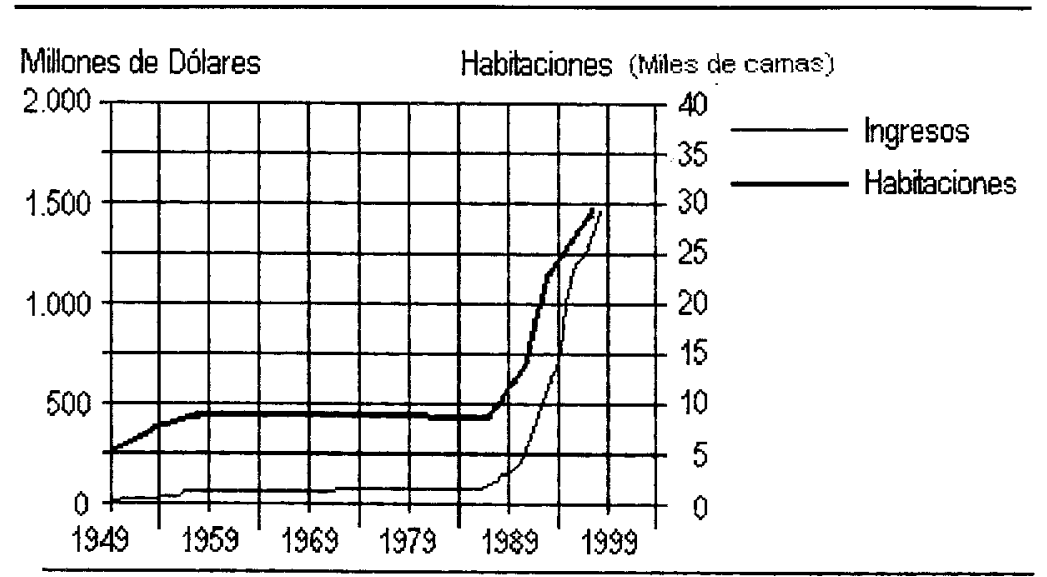

Fuente: Ministerio de Turismo de Cuba; salinas, Er. (1998); Mundet, Ll. (1998) Vtllalba, E. 1993.

por la aprobación de la Ley Seca en los Estados Unidos) el turismo mantiene sus niveles alcanzados a inicios de los años 20 e incluso se incrementa hasta su caída brusca como consecuencia de la Segunda Guerra Mundial.

Es de destacar que, según estadísticas del Banco Nacional de Cuba (Villalva, 1.993), el promedio de turistas anuales, en el periodo de 1.9341.941 fue de 134.271, con una estancia media de 8 días y un gasto por visitante de unos 100 dólares, lo que suponía ingresos anuales superiores a los 12 millones de dólares como promedio. Después de finalizada la Segunda Guerra Mundial se incrementa nuevamente el número de turistas extranjeros (especialmente norteamericanos) que visitan Cuba, aunque como también aumentan los viajes de la burguesía cubana al exterior, se origina un déficit en la balanza turística que algunos autores estimaban en más de 11 millones de dólares anuales (Villalba, 1.993), déficit que se mantuvo hasta 1.956 coincidiendo con el auge del juego y la apertura de numerosos casinos, principalmente en La Habana.

A principios de la década de los años cincuenta, Cuba se convirtió en el primer destino turístico del Caribe con más de 6.500 habitaciones y una capacidad de alojamiento de 12.067 plazas en 1.951 , recibiendo ese año 188.000 turistas, lo que representaba el $26,4 \%$ del total de visitantes del Caribe y el doble 
del segundo destino en importancia de la región, Jamaica con $13,1 \%$.

El periodo 1.952-58 representó un importante desarrollo del turismo gracias a las inversiones hoteleras que se realizaron, lo que llevó a la industria turística a ocupar el segundo lugar entre las actividades económicas del país, despuès de la producción de azúcar. En 1.957 se alcanzó la cifra más alta de turistas extranjeros con 272.265 visitantes, el $85 \%$ de los cuales procedían de Norteamérica, atraídos por la publicidad denigrante que ofrecía La Habana como centro de juegos y prostitución (Salinas Er., 1.998).

Como resumen del desarrollo del turismo en Cuba hasta el triunfo Revolucionario de 1.959 se puede señalar, "que éste estuvo sujeto a la anarquía y desidia de un sistema capitalista de subordinación al extranjero y latrocinio en la esfera pública que se tradujo en la falta de previsión en la dirección y administración, bajos ingresos por turista, estadias cortas y una pobre oferta basada esencialmente en el juego, el vicio y la prostitución" (VILLALVA, 1.993, pág. 103-104).

\section{EL TURISMO \\ DESPUÉS DE LA REVOLUCIÓN}

El turismo después de la revolución esta marcado por 3 periodos claramente diferenciados:
- El primero, desde 1.959 hasta los inicios de la década de los setenta, se caracterizó por la desaparición del turismo internacional y el acceso, por primera vez, del pueblo cubano a las instalaciones hoteleras y a conocer su país como experiencia turística nueva.

- La segunda etapa incluye los años setenta y ochenta, y está caracterizada por una lenta recuperación del turismo internacional proveniente principalmente de Europa y Canadá y la realización de los primeros proyectos de desarrollo turístico en áreas litorales e insulares del archipiélago cubano (Varadero, Cayo Coco, Cayo Largo, etc.) por instituciones académicas, el Instituto de Planificación Física y sus delegaciones provinciales

- Por último, el tercer periodo que comenzó en 1.989 con la caída del campo socialista, lo que representó un duro golpe para la economía cubana, que perdió el $80 \%$ de sus exportaciones e importaciones y supuso una caída del $35 \%$ del PIB y obligó al gobierno cubano a considerar al turismo como la única alternativa posible para la recuperación y reactivación económica del país. Ésto conllevó un proceso de construcción de nuevas capacidades hoteleras, el desarrollo de infraestructura turística y la participación 
cada vez mayor del capital extranjero en este sector.

Indicadores turísticos actualizados muestran que si en 1.987 Cuba recibió 290.000 turistas, 10 años después esta cifra se multiplicó por cuatro. Los ingresos en este mismo periodo pasaron de 165 millones de dólares en 1.987 a 1.500 millones en 1.997, mientras el número de habitaciones creció de 7.500 a 27.400 repartidas en 179 hoteles donde trabajaban 70.500 personas.

La tasa de crecimiento promedio anual del número de visitantes entre 1.990 y 1.997 fue del 19,3\%, superior al modesto $4,3 \%$ del Caribe y sólo comparable con los crecimientos experimentados en algunos países de la región de Asia meridional y Pacífico (Filipinas, Taiwan, etc.). Ésto llevó a Cuba a pasar del noveno al quinto lugar entre los países receptores de turismo en el Caribe y del lugar 23 al 13 en las Américas en su conjunto.

Como estrategia de consolidación de la industria turística en Cuba, en 1.994 se crea el Ministerio de Turismo, encargado del control, fiscalización y dirección de las actividades del sector y se desagrega y fortalece la gestión del alojamiento en diversas cadenas hoteleras (Gran Caribe, Horizontes, Isla Azul, Cubanacan, Gaviota y Cubamar) y se crean numerosas agencias y empresas para los servicios extrahoteleros, trans- porte, náutica, comercialización y excursiones, entre otros.

A partir de 1.996 el turismo pasó a ser la actividad económica más importante de Cuba quedando el azúcar (producto emblemático de la isla) en un segundo lugar. En 1.997 los hoteles bajo administración extranjera $(21,2 \%$ de los 179 que operaban en el archipiélago) aportaron el $44,8 \%$ de los ingresos generados por el turismo con una ocupación lineal del 64,6\% (ANOCETO, 1.998).

\section{ORGANIZACIÓN TERRITORIAL Y PLANIFICACIÓN DEL TURISMO EN CUBA}

A diferencia de otras actividades socio-económicas de localización más libre, el turismo generalmente suele desarrollarse allí donde las condiciones naturales o histórico-culturales, constituyen por sí mismas atractivos importantes, consumiéndose gran parte de los bienes y servicios generados por la actividad en el lugar a donde llegan los turistas. Ello implica que no puede esperarse que el turismo lleve automáticamente al desarrollo territorial equilibrado o que contribuya a eliminar las desigualdades económicas existentes, pues al contrario puede agravar estas últimas o entrar en contradicción con otros sectores de la economía (Castellanos y LanZA, 1.997). El ordenamiento del turismo, por lo tanto, debe considerar: 
-La localización espacial de la infraestructura de alojamiento y los servicios.

-Las vías de acceso y su

equipamiento.

-La localización de los recursos

humanos.

-Las áreas recreativas y lugares de interés.

-La demanda del mercado.

Hasta hace unos años la consideración de las condiciones naturales en los proyectos de ordenamiento territorial desarrollados en Cuba jugaron un papel principal en las etapas de diagnóstico y síntesis de la problemática; no obstante, este examen se realizaba con el objetivo de adecuar la actividad que se proyectaba al recurso que lo sustentaba. Es decir, se proyectaba sobre la naturaleza y no desde ella.

Esta consideración reduccionista y parcial de la problemática ambiental en el desarrollo turístico, ha provocado un conjunto de problemas, entre los que cabe destacar, la erosión de las costas, la antropización exagerada del paisaje, la pérdida de la biodiversidad, la contaminación del mar y el uso de cargas excesivas y altas densidades constructivas que han conllevado a la desvalorización de los productos turísticos (CAsteLLANOS Y LANZA, 1.997).

En los últimos años se ha introducido en los trabajos de planificación y ordenamiento del turismo en Cuba la concepción holística y sistémica conocida como planificación ambiental (ecológica, estratégica, etc.), que examina en primer lugar las condiciones naturales con el objetivo de delimitar los geosistemas ambientalmente sensibles que deben ser preservados o utilizados con fuertes restricciones, quedando entonces por exclusión las áreas con posibilidades para el desarrollo de la actividad económica que se considere (SALINAS, Ed. 1.996 y 1.997; LANZA y otros, 1.996). Este nuevo enfoque de la planificación y ordenamiento aplicado al turismo debe garantizar ante todo:

-La integridad física de los espacios.

-El desarrollo de tecnologías blandas.

-El estudio de los mercados.

-El control y vigilancia de los impactos que no pudieron ser eliminados. -La articulación de lo ambiental, social y cultural con las estructuras espaciales subyacentes, de forma óptima, integrada y participativa (LeDO, T., 1.999).

\section{PRINCIPALES REGURSOS TURÍSTICOS DE CUBA}

El archipiélago cubano constituido por la isla de Cuba, la mayor de las Antillas con una longitud de este a oeste de $1.138 \mathrm{Km}$., la Isla de la Juventud y más de 4.000 pequeñas islas que rodean por el norte y el sur a la isla principal, 
presenta una amplia variedad de recursos naturales e histórico-culturales para el desarrollo del turismo.

Su posición geográfica tropical, la insularidad y la evolución geólogo-geomorfológica particular condicionan una gran diversidad y complejidad de los paisajes de Cuba, donde predominan los paisajes de llanuras, existe una amplia distribución de los paisajes kársticos y se origina una diferenciación altitudinal de los mismos más compleja que en las áreas continentales (SALINAS, Ed., 1.996).

Como consecuencia de lo anterior, existen numerosas y bellas playas de gran extensión, con arenas blancas y finas (más de $345 \mathrm{Km}$.) que se combinan con costas abrasivas (acantiladas) y biogénicas (manglares) y donde encontramos aguas cálidas y transparentes; espectaculares fondos marinos con una variada flora y fauna y extensos arrecifes coralinos, todo lo cual aumenta la diversidad paisajística y permite desarrollar variadas actividades recreativas tanto en tierra como en el mar.

La flora de Cuba es una de las más ricas del mundo con más de 7.000 especies de plantas, con un endemismo superior al $51 \%$ y más de 900 especies en las diversas categorías de vulnerabilidad y peligro de extinción, lo que representa el 2,25\% de la flora mundial y la convierte en una de las 10 regiones biológicas más ricas del mundo, constitu- yéndose a la vez en un recurso turístico importante de cara a las crecientes demandas de un turismo más cercano a la naturaleza.

Sumado a estos recursos naturales, el archipiélago cubano presenta destacados recursos socio-culturales asociados a la mezcla de razas originada a partir de su conquista y colonización hace más de 5 siglos, lo que provocó la gran riqueza socio-cultural del pueblo cubano que se refleja en sus costumbres, forma de hablar y de vestir, música, carácter hospitalario y gastronomía entre otros (RIVERo DE LA CALle, 1.992) y que se aprecian en la arquitectura de sus ciudades, en el cultivo y producción de tabaco, azúcar, café y ron, así como en el sincretismo religioso, entre otros.

Los recursos turísticos con que cuenta Cuba son suficientes para ofrecer a los visitantes un producto turístico diversificado e integral que por sus características tenga aceptación en el mercado internacional y sea competitivo a nivel regional (SALINAS, ER. Y BENAVIDES, 1.995).

\section{DISTRIBUCIÓN ACTUAL Y FUTURA DE LA CAPACIDAD HOTELERA DE GUBA}

La distribución de la capacidad hotelera en 1.995 reflejaba una gran polarización hacia las playas y ciudades, que concentraban casi el $90 \%$ del total de plazas turísticas del país. El desarrollo turístico del país que se basa en diversos 
Figura 3. Distribución de la Capacidad Hotelera en Cuba

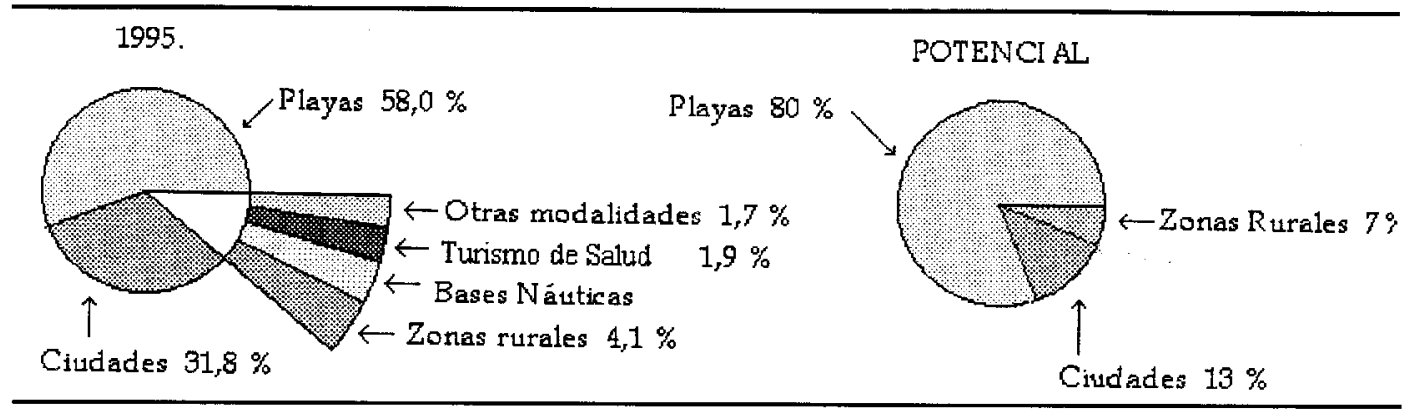

Fuente: Campos, R. (1995). Mundet, Ll. (1.998).

estudios del Instituto de Planificación Física, el Ministerio del Turismo y otras instituciones, contempla la existencia de más de 1.200 atractivos naturales e histórico-culturales y un potencial de más de 150.000 habitaciones distribuidas en 85 polos turísticos. Según otros autores, la capacidad potencial del archipiélago es superior a las 200.000 habitaciones nuevas (Salinas, ER., 1.994).

Por la necesidad de optimizar los recursos financieros y humanos existentes, así como para aprovechar la infraestructura técnica creada, se han prioriza-

Figura 4. Principales Regiones Turísticas de Cuba

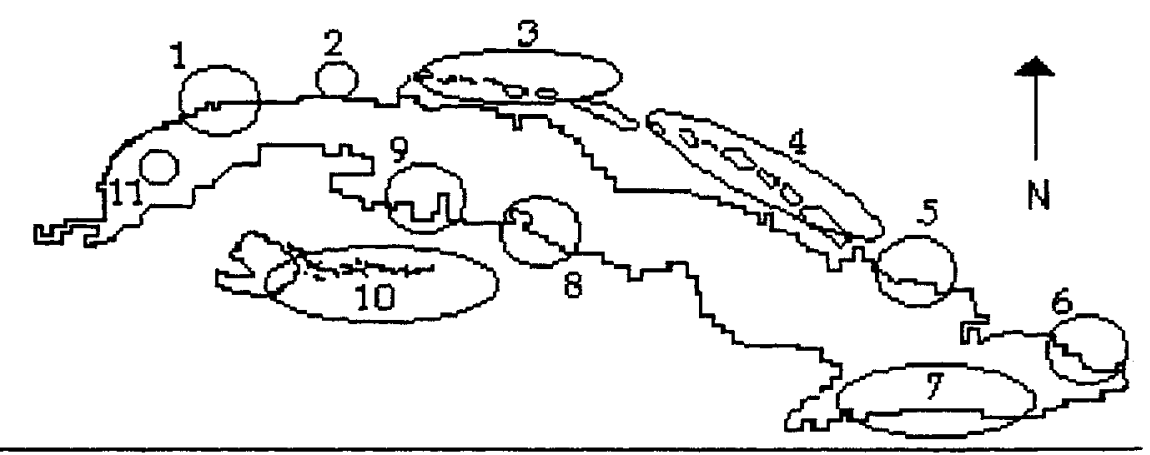

1. Ciudad de La Habana; 2. Playa de Varadero; 3. Costa Norte de Villa Clara; 4. Costa Norte de Ciego de Ávila-Camagüey; 5. Costa Norte de Holguin; 6. Baracoa; 7. Costa Sur de Sierra Maestra; 8. Trinidad-Topes de CollantesCienfuegos; 9. Parque Natural de Montemar (Bahía de Cochinos); 10. Isla de la Juventud-Cayo Largo; 11 . Valle de Viñales. 
do 11 regiones para el desarrollo del turismo en el archipiélago cubano, que agrupan 50 polos turísticos e incluyen el $90 \%$ de las capacidades hoteleras actuales y el $85 \%$ de las potenciales (estas regiones pueden ser apreciadas en la Figura 4).

Según las cifras propuestas de desarrollo de las nuevas capacidades hoteleras en el archipiélago cubano e son: $80 \%$ en áreas litorales, $13 \%$ en ciudades y el $7 \%$ restante en zonas rurales o áreas protegidas, se consagrará el modelo de turismo litoral al igual que en el resto del Caribe, lo que puede hipotecar el futuro desarrollo alternativo y diferenciado de nuevas modalidades turísticas que no tengan en el sol y la playa su principal razón de ser (Mundet y Salinas, Ed., 1.999).

\section{RETOS Y PERSPECTIVAS DE LA INDUSTRIA TURÍSTICA EN CUBA}

Según estimaciones de la OMT, el Caribe tendrá un crecimiento medio anual del $4,5 \%$ en la llegada de visitantes hasta el 2.020 , superior al $3,8 \%$ señalado como media para las Américas y al $4,3 \%$ previsto para el mundo, lo que representará la llegada de unos 40 millones de turistas a la región (OMT, 1.998). Cuba pretende alcanzar una posición cimera en el turismo caribeño que la llevaría a recibir alrededor de 10 millones de turistas para ese año y para lo cual se realizan los estudios e inversiones necesarias que permitan sostener un crecimiento de más del $10 \%$ anual en el periodo.
Según estimaciones de la OMT, Cuba debe recibir unos 2,5 millones de turistas en el año 2.000, lo que representará ingresos superiores a los 3.000 millones de dólares (duplicando las cifras de 1.997) y alcanzar las 50.000 habitaciones (incrementando su número en un $182 \%$ con respecto al año de 1.997).

Como política de desarrollo del sector, se potenciarán las formas actuales de comercialización y se incorporarán nuevas modalidades turísticas como el multidestino, el ecoturismo, el turismo náutico, de salud, deportivo, cultural, el tiempo compartido, cruceros y otras modalidades de turismo especializado, con el objetivo de diversificar la oferta turística del archipiélago, captar otros segmentos turísticos, lograr una mejor distribución espacial del turismo y afianzar el papel multiplicador de la actividad en la economía nacional.

Según palabras del Ministro de Turismo, Osmany Cienfuegos, durante la inauguración del XII Congreso de la Federación Española de Agencias de Viajes, celebrada en La Habana en Octubre de 1.994. "Cuba no es sólo sol y playa. Es mucho más que éso. Es historia, naturaleza, leyenda, un peculiar sentido de vivir. Un destino para cada deseo".

\section{VENTAJAS COMPETITIVAS DE CUBA}

- Geoecológicas: por su carácter insular tropical y su evolución geologo-geomorfológica, el archipiélago cubano presenta una gran diversidad y complejidad de 
paisajes terrestres y marinos, altas tasas de biodiversidad y endemismo de su biota. Más del $15 \%$ de su superficie está bajo diferentes regímenes de protección que protegen más del $90 \%$ de las especies vegetales y casi la totalidad de los vertebrados.

- Socioeconómicas: estabilidad política y social, población hospitalaria con un alto nivel cultural.

- Infraestructurales: amplia base vial y aeroportuaria, redes técnicas de electricidad y agua potable que cubren todo el país y capacidades de alojamiento y servicios en plena expansión.

\section{PRINCIPALES RETOS QUE DEBE SUPERAR EL SECTOR TURÍSTICO CUBANO}

El desarrollo acelerado del turismo en los últimos años, sus perspectivas de crecimiento a corto y medio plazo y su efecto dinamizador de la economía cubana, como única forma de lograr la necesaria recuperación económica del país, presupone alcanzar resultados importantes en dicha actividad, para lo cual deberán tomarse en cuenta los aspectos siguientes:

- Incrementar los aportes netos por concepto del turismo al país (35\% o más anualmente).

- Disminuir los costos por peso o dólar invertido, incrementando la rentabilidad.
- Racionalizar las inversiones y realizar proyectos más viables.

- Lograr una mayor y mejor comercialización del producto turístico cubano.

- Obtener una verdadera calidad y eficiencia en la gestión.

- Elevar la ocupación lineal de las instalaciones a más del $70 \%$.

- Acelerar la construcción de nuevas capacidades de alojamiento e incrementar y mejorar la planta hotelera en explotación, elevando la calidad de las mismas.

- Garantizar un crecimiento continuo de la participación de los productos cubanos en los insumos del turismo.

- Lograr una mayor autonomía en la toma de decisiones por parte de las entidades turísticas junto a un mayor control y fiscalización de sus actividades por el estado.

- Mejorar la calidad y oferta de los servicios prestados al turista, lo que elevará el índice de retorno de los visitantes actualmente inferior al $10 \%$.

- Afrontar los impactos sociales y culturales derivados del desarrollo del turismo en el país.

- Continuar trabajando en la diversificación del producto turístico cubano.

\section{CONCLUSIONES}

El Caribe insular y Cuba en particular, seguirán experimentando crecimientos 
del turismo en las próximas décadas superiores a la media mundial, lo que representa un reto para sus economías y pueblos que deberán continuar trabajando conjuntamente en la consolidación de la primera Zona de Turismo Sustentable del mundo.

Aunque el turismo suele desarrollarse donde las condiciones y recursos naturales o histórico-culturales se constituyen en atractivos importantes, ello no excluye el que se pueda elaborar una política adecuada para su desarrollo.

Cuba presenta importantes recursos turísticos, tanto naturales como socio-culturales que le permiten ofrecer al turista un producto diversificado e integral que sea competitivo y permita alcanzar la sustentabilidad económica, social y ecológica de la actividad.

Por el efecto potenciador y dinamizador del turismo sobre otras actividades económicas, su planificación y ordenamiento debe realizarse de forma integrada a escalas nacional y regional.

Debe lograrse la integración del turismo con la población local ya que ésta es beneficiosa social, cultural y económicamente.

Resulta imprescindible incorporar, cada vez más, la dimensión ambiental en la elaboración de los planes de desarrollo turístico del país, lo que implica la adecuada conciliación del desarrollo eficiente de la ạctividad con la protección del medio ambiente; es decir, proyectar su desarrollo desde la naturaleza.

El turismo en Cuba ha tenido en los últimos años un crecimiento explosivo que debe continuar en las próximas dos décadas. Ésto no ha estado acompañado del desarrollo económico de otras actividades y ha ocasionado importantes impactos sociales, lo que hace necesario trabajar aceleradamente con vistas a incrementar su papel dinamizador de la economía y disminuir los conflictos sociales generados.

Aunque el desarrollo de nuevas capacidades está previsto que incremente el papel del turismo de playa y de ciudad en Cuba, deben tomarse en cuenta otras consideraciones con vistas a no hipotecar el futuro desarrollo alternativo y diferenciado de nuevas modalidades turísticas y aprovechar las ventajas competitivas del país.

Se han planteado una serie de aspectos a tomar en cuenta si se quiere alcanzar un turismo de excelencia que sea soportable en lo ecológico, factible en lo económico y equitativo desde el punto de vista ético y social para el pueblo cubano. Ésto presupone afrontar y superar los retos planteados al turismo en Cuba, sin dejar por ello de desarrollar el turismo como lo requiere la economía del país en la actualidad. 